\title{
Influence of seed aerosol surface area and oxidation rate on vapor wall deposition and SOA mass yields: a case study with $\alpha$-pinene ozonolysis
}

Theodora Nah et al.

Correspondence to: Nga L. Ng (ng@chbe.gatech.edu)

The copyright of individual parts of the supplement might differ from the CC-BY 3.0 licence. 

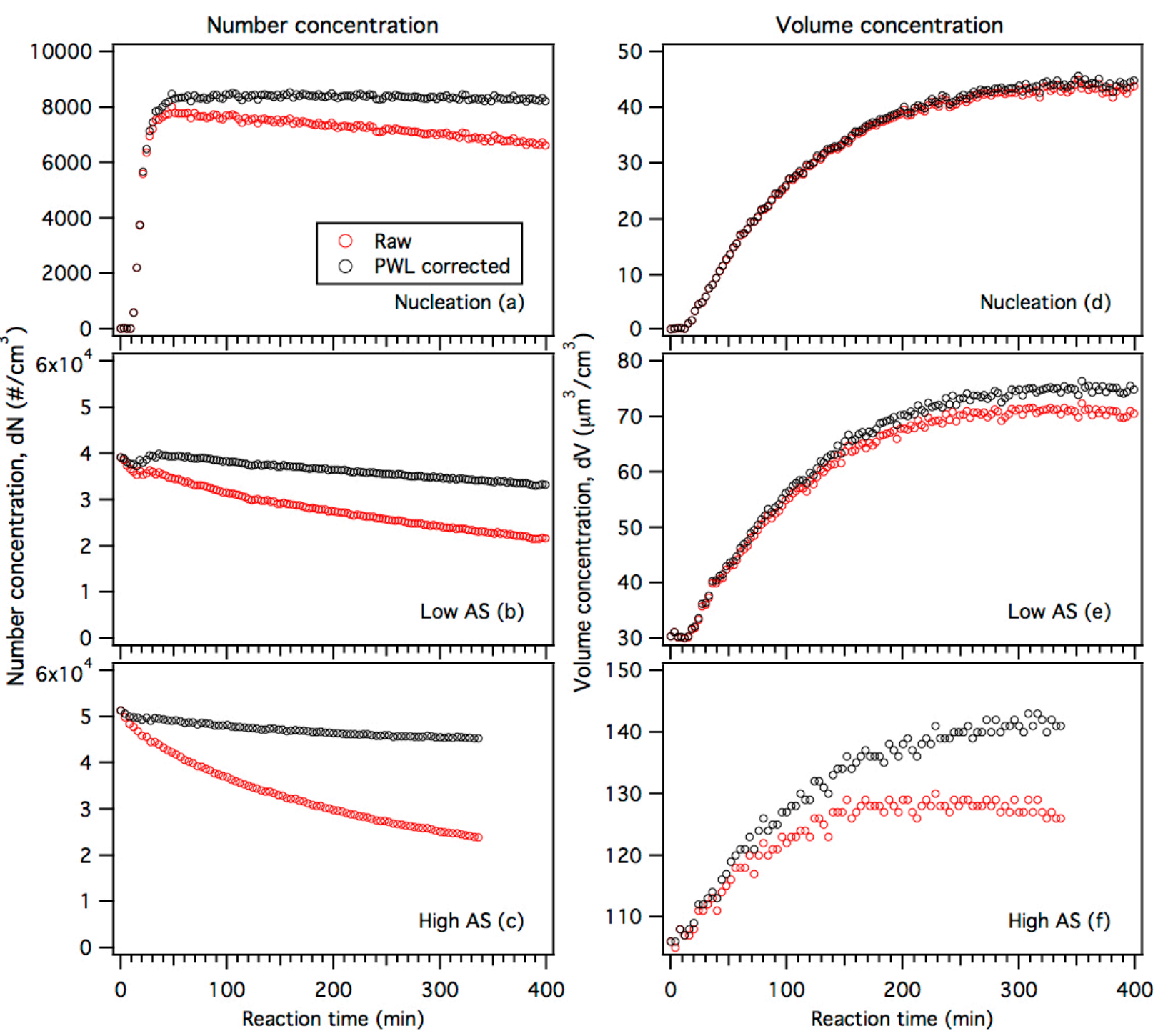

16 Figure S1: Raw and particle wall loss (PWL) corrected number and volume 17 concentration data for the $100 \mathrm{ppb} \mathrm{O}_{3}$ experiments. Raw nucleation (panels a and d) and 18 low AS (panels $\mathrm{b}$ and e) data are particle wall loss corrected using particle wall loss rates 19 determined from the low AS-seed only experiments. Raw high AS (panels $\mathrm{c}$ and f) data 20 are particle wall loss corrected using particle wall loss rates determined from the high 21 AS-seed only experiments. 

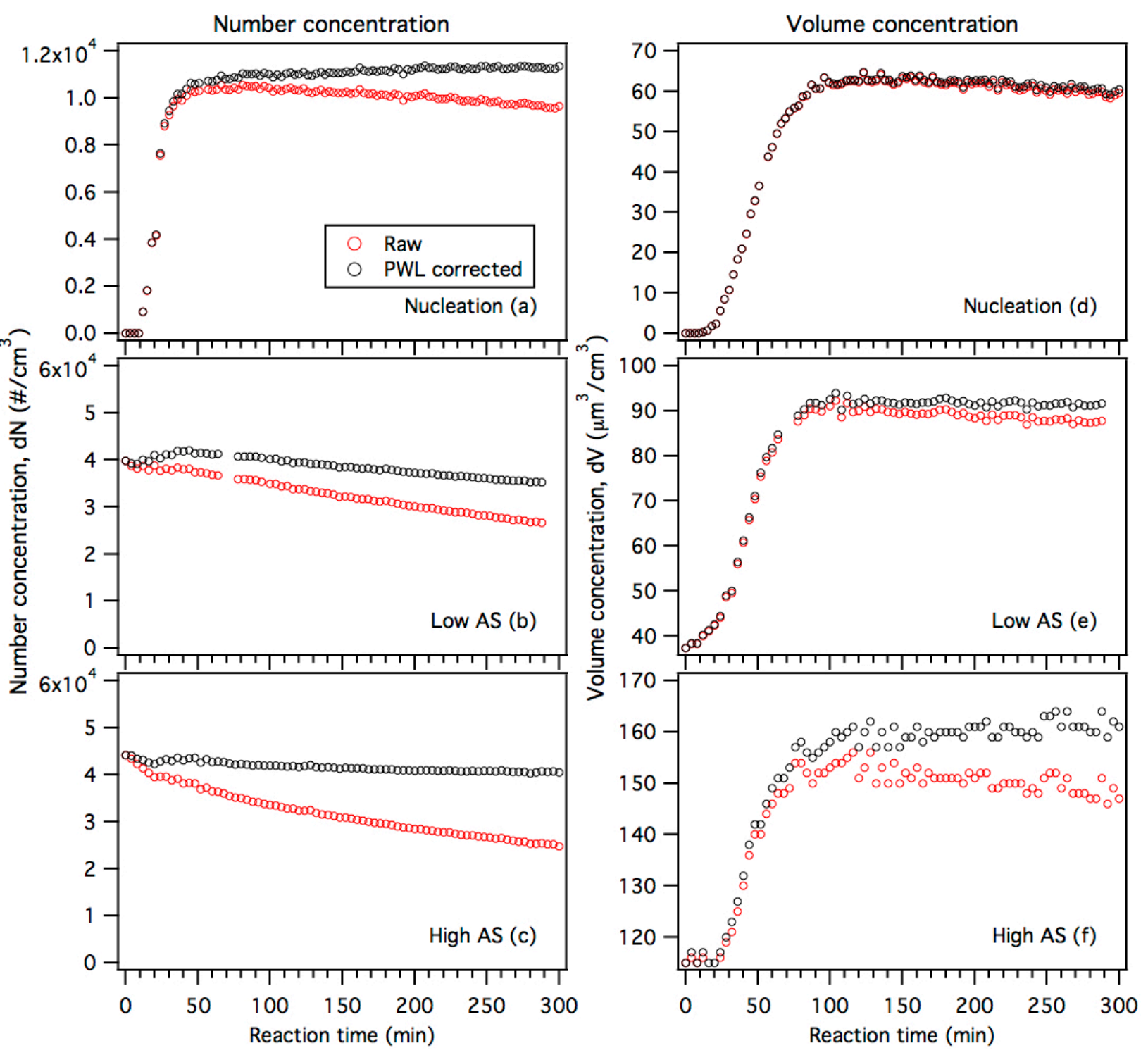

23 Figure S2: Raw and particle wall loss (PWL) corrected number and volume concentration data for the 500 ppb $\mathrm{O}_{3}$ experiments. Raw nucleation (panels a and d) and low AS (panels $b$ and e) data are particle wall loss corrected using particle wall loss rates

26 determined from the low AS-seed only experiments. Raw high AS (panels $\mathrm{c}$ and f) data

27 are particle wall loss corrected using particle wall loss rates determined from the high

28 AS-seed only experiments. 

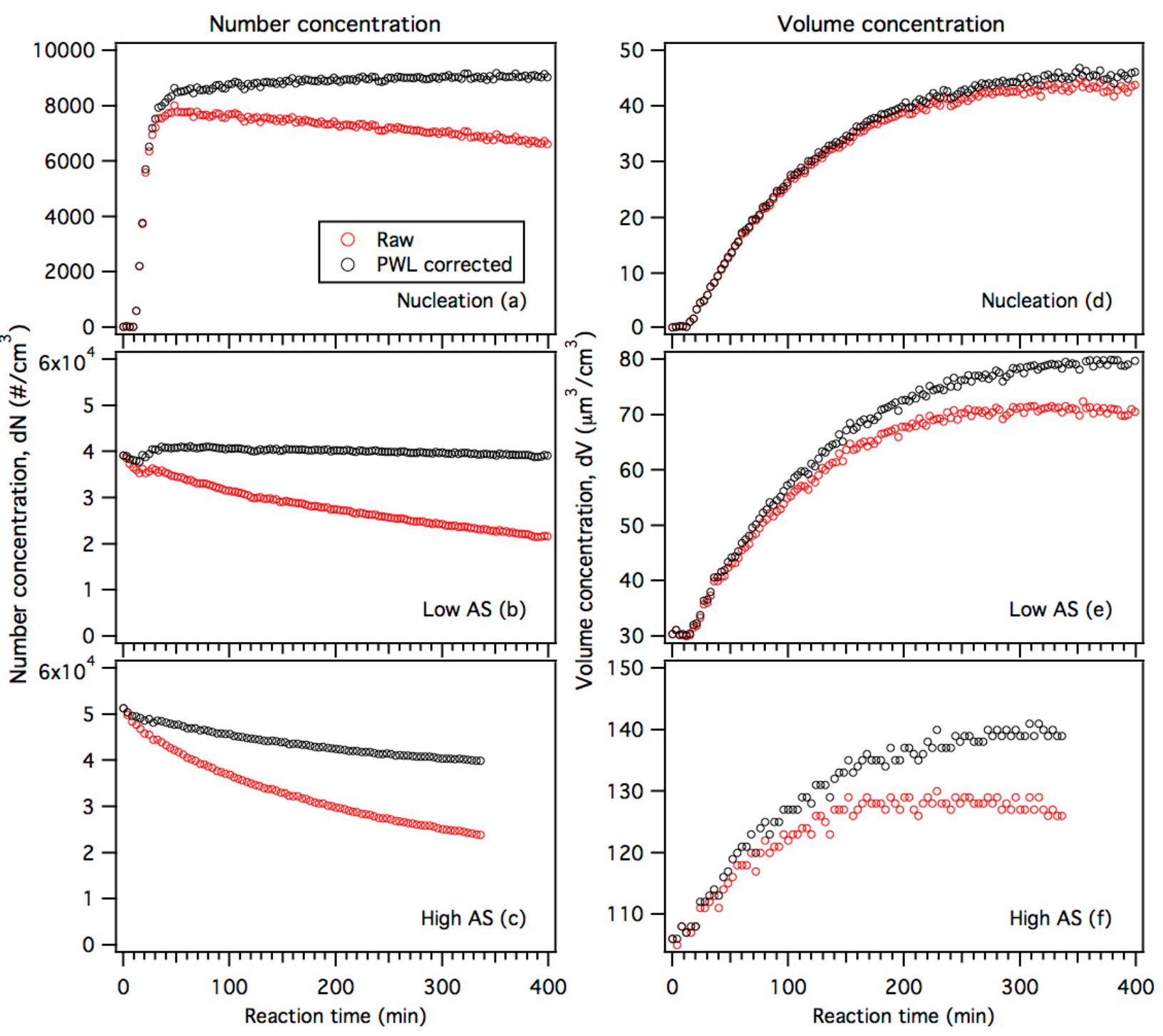

30 Figure S3: Raw and particle wall loss (PWL) corrected number and volume 31 concentration data for the $100 \mathrm{ppb} \mathrm{O}_{3}$ experiments. All the raw data are particle wall loss 32 corrected using the average particle wall loss rates (i.e. average of the particle wall loss 33 rates obtained from low AS-seed only and high-AS seed only experiments). 

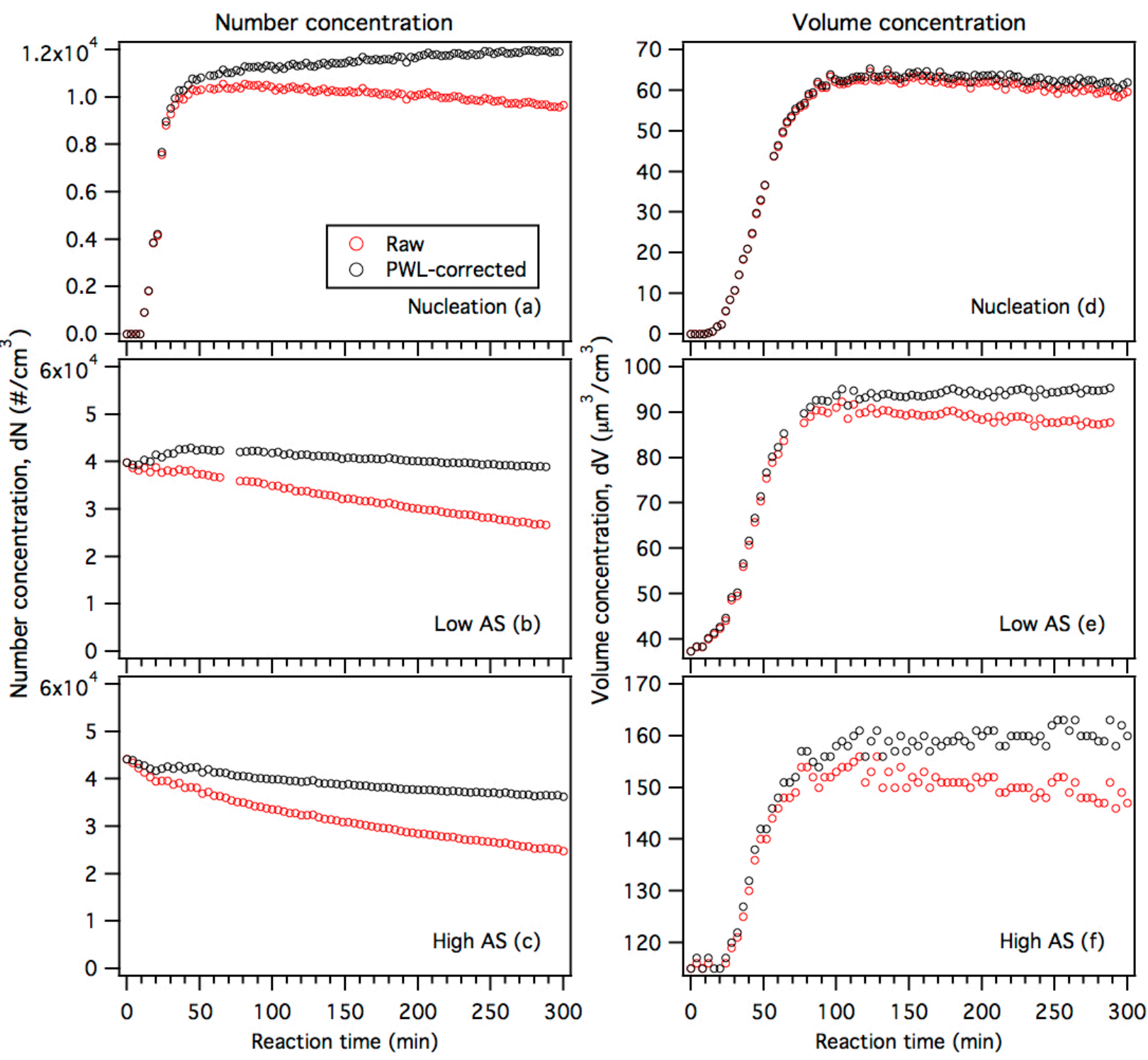

Figure S4: Raw and particle wall loss (PWL) corrected number and volume 36 concentration data for the $500 \mathrm{ppb} \mathrm{O}_{3}$ experiments. All the raw data are particle wall loss 37 corrected using the average particle wall loss rates (i.e. average of the particle wall loss 38 rates obtained from low AS-seed only and high-AS seed only experiments). 


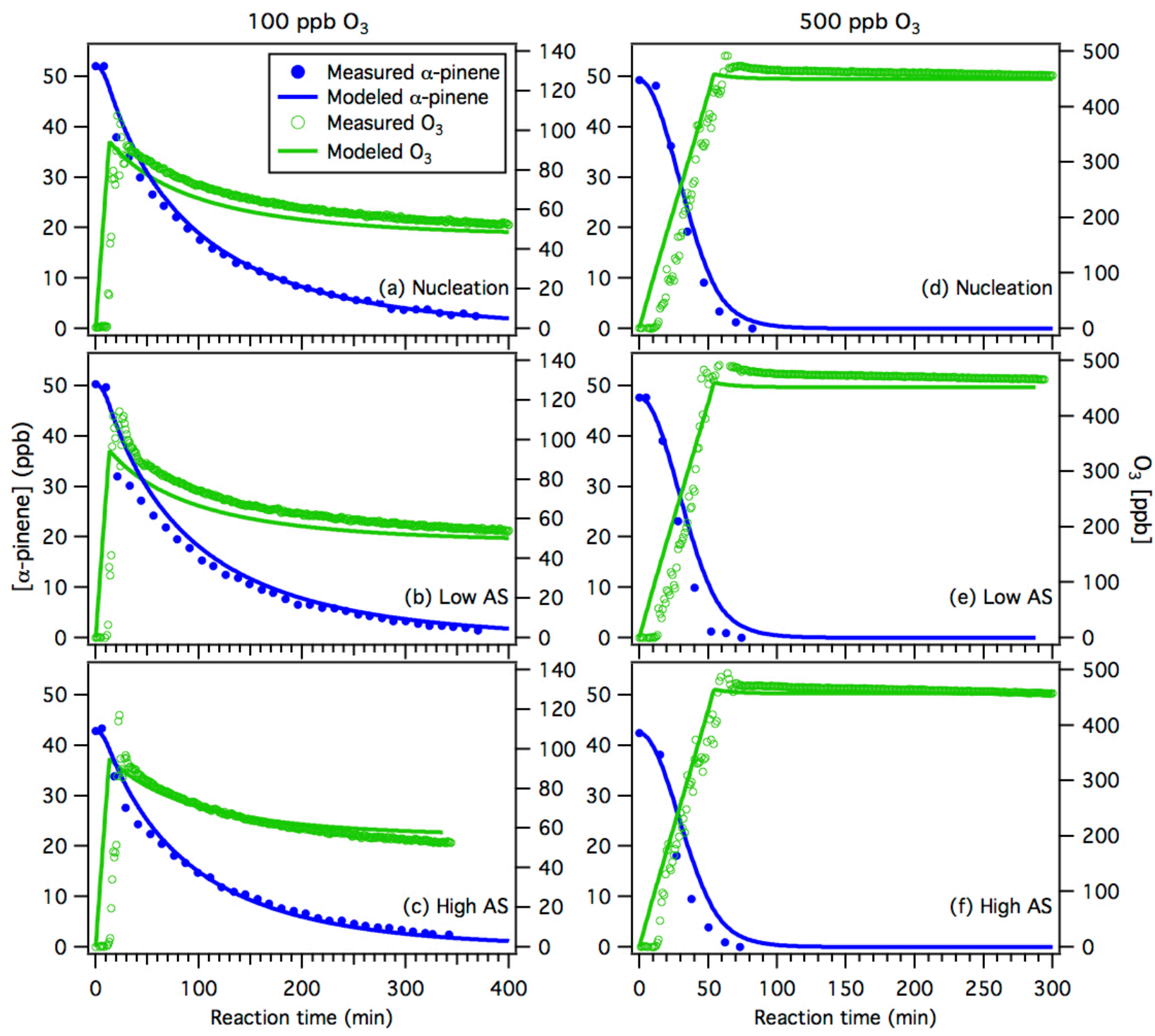

Figure S5: Reaction profiles of the measured and modeled $\mathrm{O}_{3}$ and $\alpha$-pinene concentration in the $\alpha$-pinene ozonolysis experiments. Panels (a), (b) and (c) show results

42 from the nucleation, low AS and high AS $100 \mathrm{ppb} \mathrm{O}_{3}$ experiments, respectively. Panels

43 (d), (e) and (f) show results from the nucleation, low AS and high AS 500 ppb $\mathrm{O}_{3}$

44 experiments, respectively. The blue lines that fit the $\alpha$-pinene concentration 45 measurements and the green lines that fit the $\mathrm{O}_{3}$ concentration measurements are model 46 simulation results that come from the coupled vapor-particle dynamics model described 47 in Section 3. 


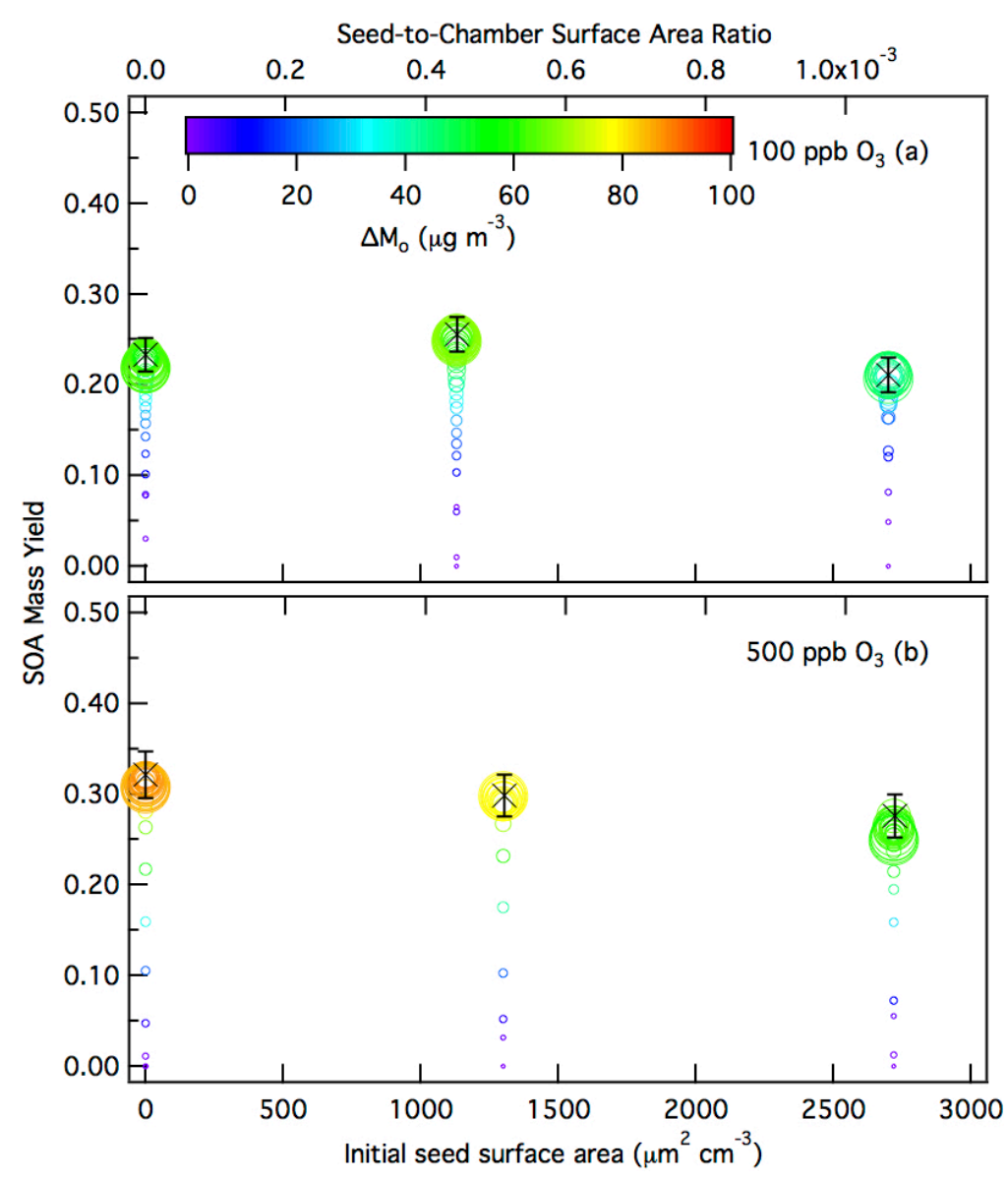

50 Figure S6: 10 min-averaged SOA mass yields over the course of an $\alpha$-pinene ozonolysis 51 experiment as a function of initial total AS seed surface area concentration for the (a) 100 $52 \mathrm{ppb} \mathrm{O}_{3}$ experiments, and (b) $500 \mathrm{ppb}_{3}$ experiments. Here, all the data have been 53 particle wall loss corrected using the average particle wall loss rates (i.e. average of the 54 particle wall loss rates measured from low AS-seed only and high-AS seed only 55 experiments). Symbol color indicates the SOA mass concentration and symbol size 56 indicates the time after $\mathrm{O}_{3}$ is injected into the chamber. The $\times$ symbols are the SOA mass 57 yields at peak SOA growth. The y-axis error bars represent the uncertainty in the peak 58 SOA mass yield, which originates from the $\alpha$-pinene injection and the aerosol volume 59 concentration measured by the SMPS at peak SOA growth (one standard deviation). As 60 discussed in the main text, the use of average measured particle wall loss rates for particle 61 wall loss correction does not change the conclusions of this work: 1) SOA mass yields 62 are enhanced at higher $\mathrm{O}_{3}$ concentrations, and 2) there is a lack of a SOA mass yield 63 dependence on the seed surface area within the range of AS seed surface area 64 concentration used in this study. 

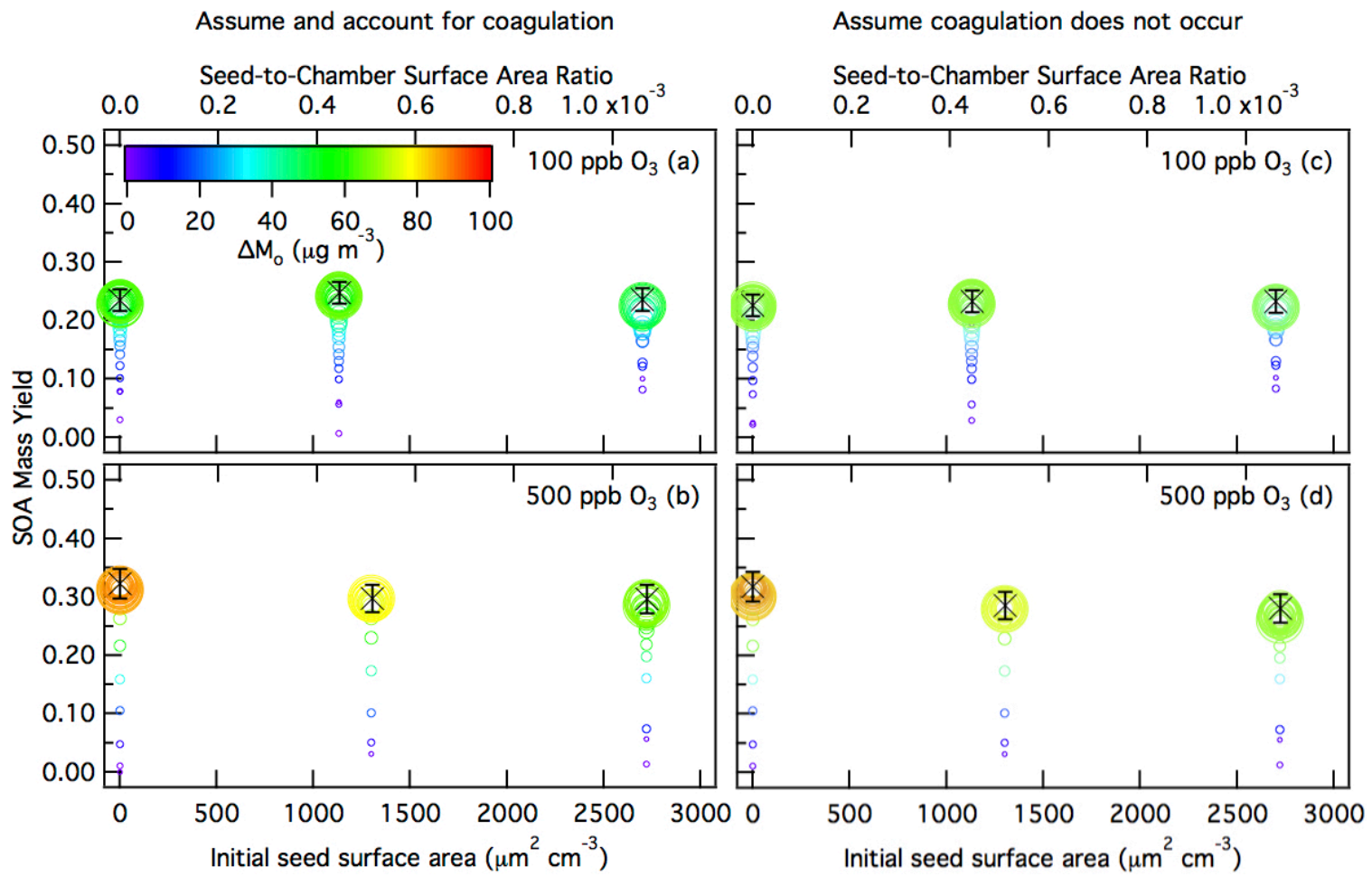

66 Figure S7: 10 min-averaged SOA mass yields over the course of an $\alpha$-pinene ozonolysis experiment as a function of initial total AS seed surface area concentration. Panels (a) and (b) show the SOA mass yields obtained using the coagulation-corrected sizedependent particle wall deposition coefficients for the 100 and $500 \mathrm{ppb}_{3}$ experiments, respectively. Panels (c) and (d) show the SOA mass yields obtained using the measured size-dependent particle wall deposition coefficients (that account for coagulation) for the 100 and 500 ppb $\mathrm{O}_{3}$ experiments, respectively (also shown in Fig. 4 of the main text). Symbol color indicates the SOA mass concentration and symbol size indicates the time after $\mathrm{O}_{3}$ is injected into the chamber. The $X$ symbols are the SOA mass yields at peak SOA growth. The y-axis error bars represent the uncertainty in the peak SOA mass yield, which originates from the $\alpha$-pinene injection and the aerosol volume concentration measured by the SMPS at peak SOA growth (one standard deviation). As discussed in the main text, the use of coagulation-corrected particle wall deposition coefficients for particle wall loss correction does not change the conclusions of this work: 1) SOA mass yields are enhanced at higher $\mathrm{O}_{3}$ concentrations, and 2) there is a lack of a SOA mass

81 yield dependence on the seed surface area within the range of AS seed surface area 82 concentration used in this study. 


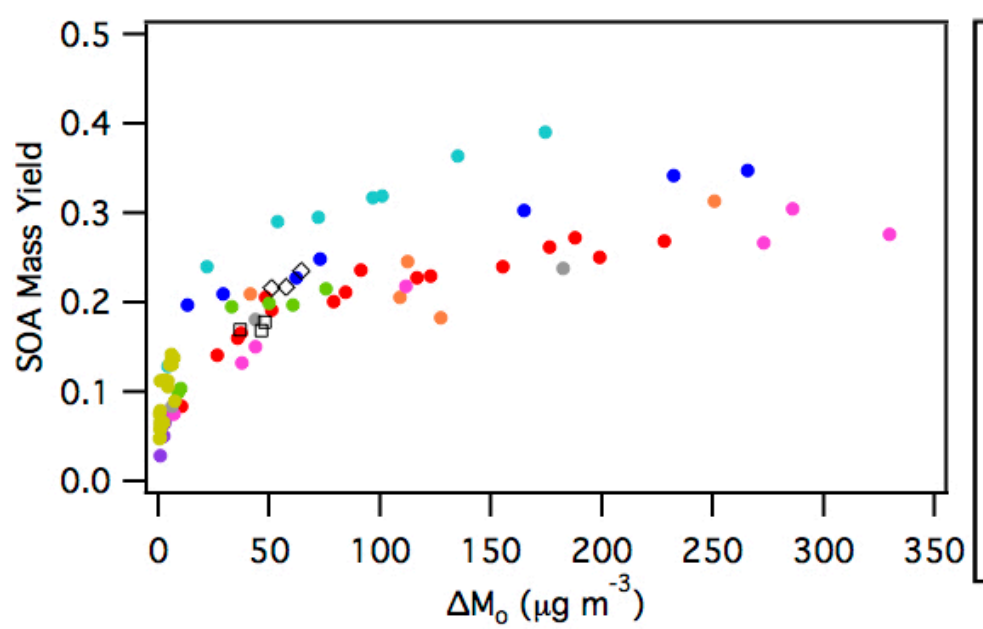
- Hoffmann et al. (1997) Griffin et al. (1999)
- Cocker et al. (2001b)
- Gao et al. (2004)
- Presto et al. (2005)
- Presto et al. (2006)
- Pathak et al. (2007b)
- Song et al. (2007)
Shilling et al. (2008)
This study $100 \mathrm{ppb} \mathrm{O}_{3}$
$\diamond$ This study $500 \mathrm{ppb} \mathrm{O}_{3}$

85 Figure S8: Comparison of SOA mass yields obtained using the coagulation-corrected size-dependent particle wall deposition coefficients to those of previous dark $\alpha$-pinene ozonolysis studies (Table S2). The SOA mass yields and concentrations of majority of these previous studies (Hoffmann et al., 1997; Griffin et al., 1999; Cocker et al., 2001b; Gao et al., 2004; Presto et al., 2005; Presto et al. 2006; Pathak et al., 2007b; Song et al., 2007) were previously compiled by Shilling et al. (2008). Similar to Shilling et al. (2008), all the data shown here (including those reported in this study) have been adjusted using an organic density of $1.0 \mathrm{~g} \mathrm{~cm}^{-3}$, and to $298 \mathrm{~K}$ using a temperature correction of $1.6 \%$

93 per K, as recommended by Pathak et al. (2007b) to facilitate easier comparison among 94 the different studies. 

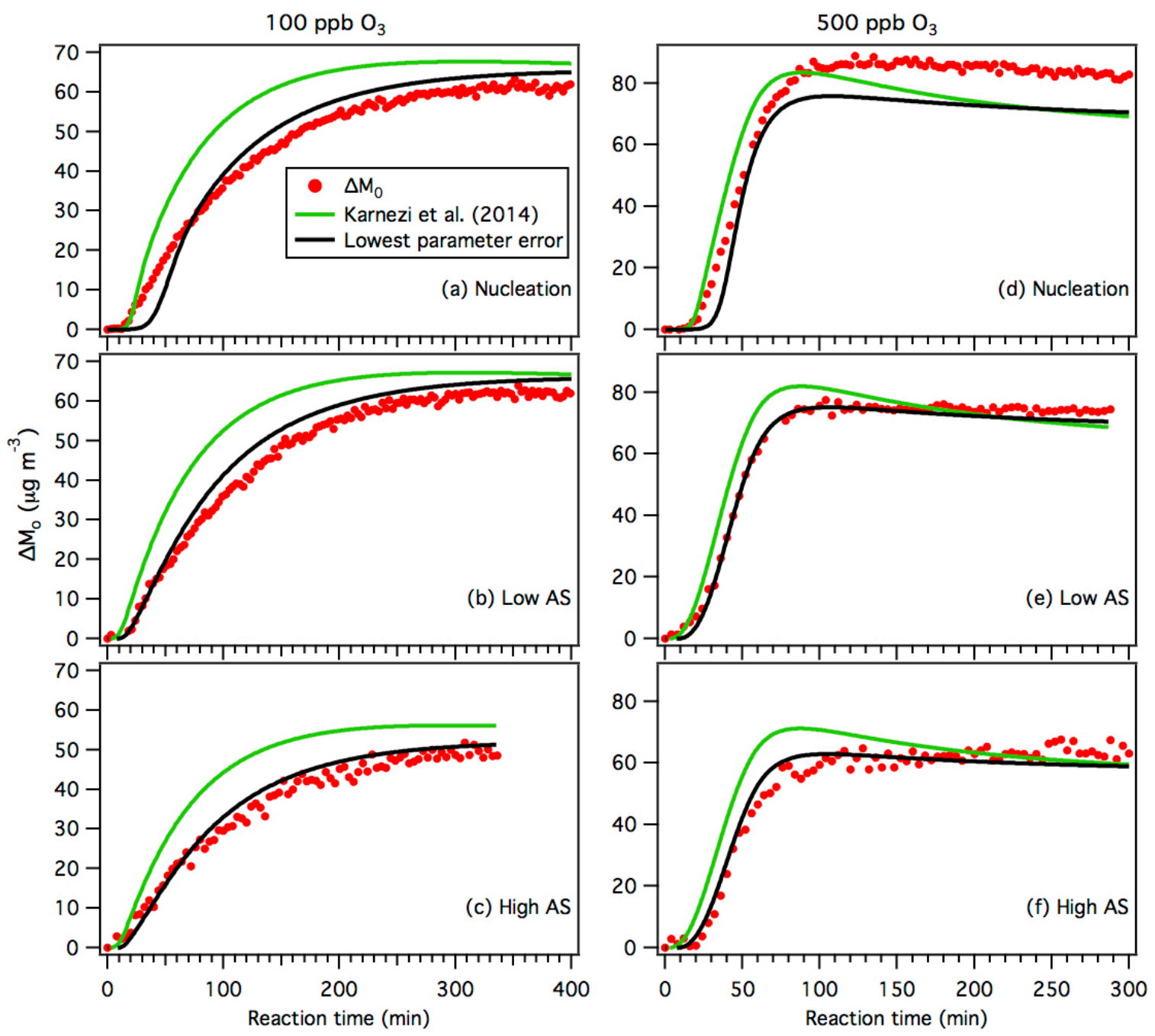

Figure S9: Reaction profiles for measured and modeled SOA concentration, using both

110 the Karnezi et al. (2014) parameters and the lowest-error combination of parameters (see 111 Table S4). Panels (a), (b) and (c) show results from the nucleation, low AS and high AS $112100 \mathrm{ppb} \mathrm{O}_{3}$ experiments, respectively. Panels (d), (e) and (f) show results from the 113 nucleation, low AS and high AS 500 ppb $\mathrm{O}_{3}$ experiments, respectively. 


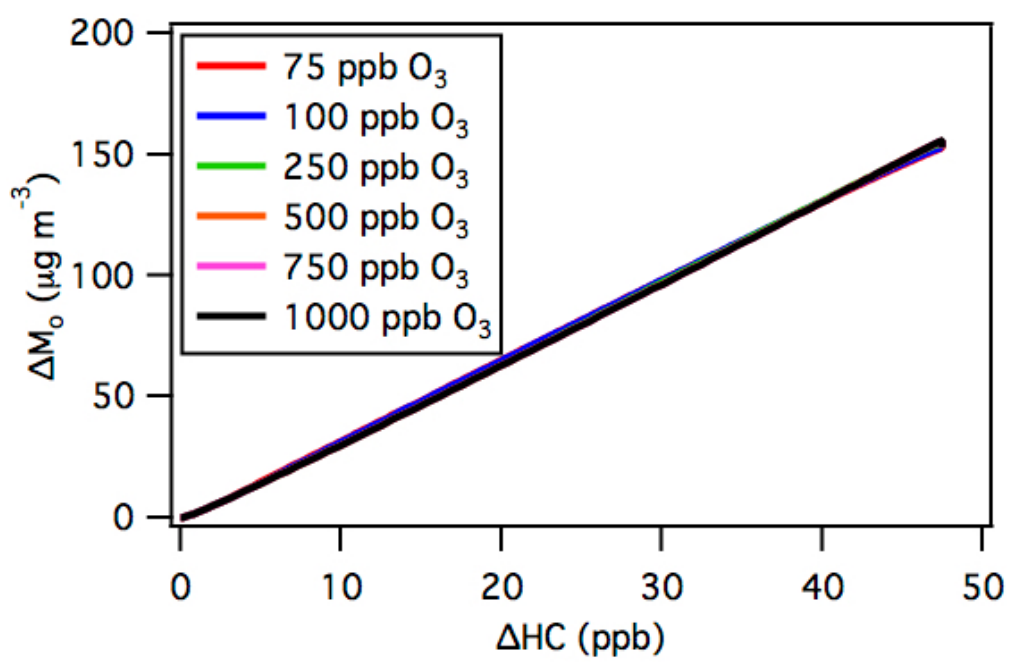

118

$\Delta \mathrm{HC}(\mathrm{ppb})$

119 Figure S10: Results from the coupled vapor-particle dynamics model showing how SOA 120 mass concentration $\left(\Delta \mathrm{M}_{0}\right)$ changes as a function of reacted $\alpha$-pinene at different $\mathrm{O}_{3}$ 121 concentrations, assuming all the $\alpha$-pinene oxidation products are non-volatile. In these 122 model simulation runs, the initial $\alpha$-pinene concentration is fixed at $48 \mathrm{ppb}$, while the $\mathrm{O}_{3}$ 123 concentration is varied from 75 to $1000 \mathrm{ppb}$. The $\mathrm{O}_{3}$ injection rate used in these model 124 simulation runs is $500 / 54.25 \mathrm{ppb} \mathrm{min}^{-1}$.

125

126

127

128

129

130

131 


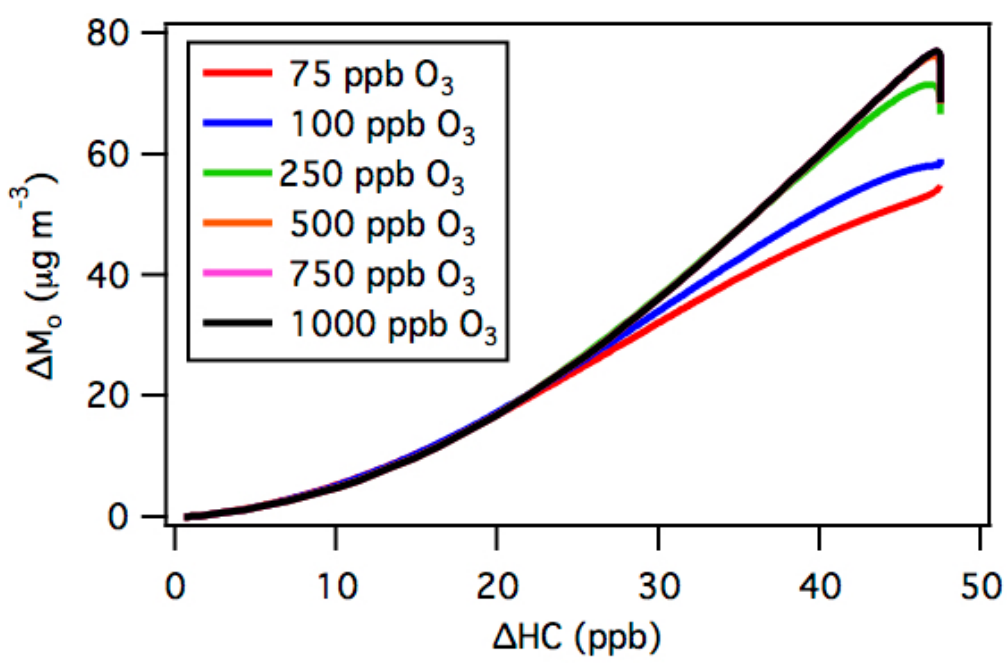

$\Delta \mathrm{HC}(\mathrm{ppb})$

133 Figure S11: Predictions from the coupled vapor-particle dynamics model showing time134 dependent growth curves for SOA formation from $\alpha$-pinene ozonolysis at different $\mathrm{O}_{3}$ 135 concentrations. In these model simulation runs, the initial $\alpha$-pinene mixing ratio is fixed 136 at $48 \mathrm{ppb}$, while the $\mathrm{O}_{3}$ mixing ratio is increased from 75 to $1000 \mathrm{ppb}$. In the model, the $137 \mathrm{O}_{3}$ injection rate is assumed to be fixed at $500 / 54.25 \mathrm{ppb} \mathrm{min}^{-1}$, and the injection time is 138 increased to achieve the desired $\mathrm{O}_{3}$ concentration (i.e., $75,100,250,500,750$ or 1000 $139 \mathrm{ppb})$ in the chamber. The predicted $\Delta \mathrm{M}_{\mathrm{o}}$ decreased slightly at the end of the experiment 140 at the higher $\mathrm{O}_{3}$ concentrations $(250,500,750$ and $1000 \mathrm{ppb})$ due to SOA evaporation. It 141 is important to note that SOA evaporation is predicted at high $\mathrm{O}_{3}$ concentrations in the 142 coupled vapor-particle dynamics model, but not observed in chamber experiments. 


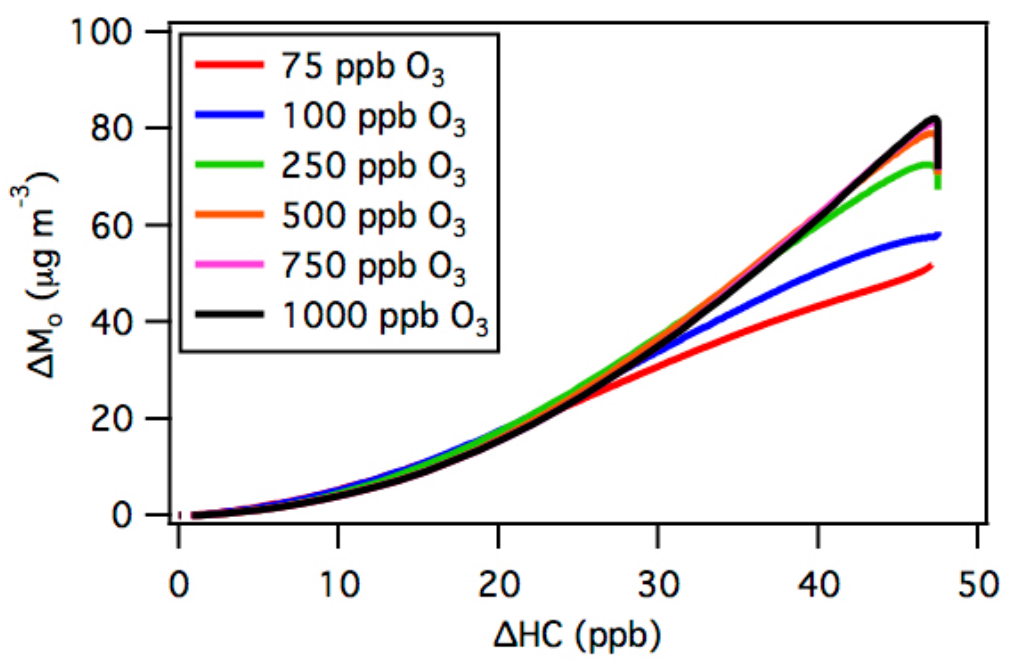

148 Figure S12: Results from the coupled vapor-particle dynamics model showing how SOA 149 mass concentration $\left(\Delta \mathrm{M}_{0}\right)$ changes as a function of reacted $\alpha$-pinene at different $\mathrm{O}_{3}$ 150 concentrations. In these model simulation runs, the initial $\alpha$-pinene concentration is fixed 151 at $48 \mathrm{ppb}$, while the $\mathrm{O}_{3}$ concentration is varied from 75 to $1000 \mathrm{ppb}$. Here, the $\mathrm{O}_{3}$ 152 injection rate is 5 times faster than the base rate used in the model. The base rate is $153500 / 54.25 \mathrm{ppb} \mathrm{min}^{-1}$, the same rate used to analyze results from the $500 \mathrm{ppb}_{3}$ 154 experiments. As discussed in the main text, the oxidation rate effect persists at a higher $155 \mathrm{O}_{3}$ concentration when a faster $\mathrm{O}_{3}$ injection rate is used. It is important to note that SOA 156 evaporation is predicted at high $\mathrm{O}_{3}$ concentrations in the coupled vapor-particle dynamics 157 model, but not observed in chamber experiments. 
168 Table S1: Initial and particle wall loss corrected final number concentrations ${ }^{\mathrm{a}}$

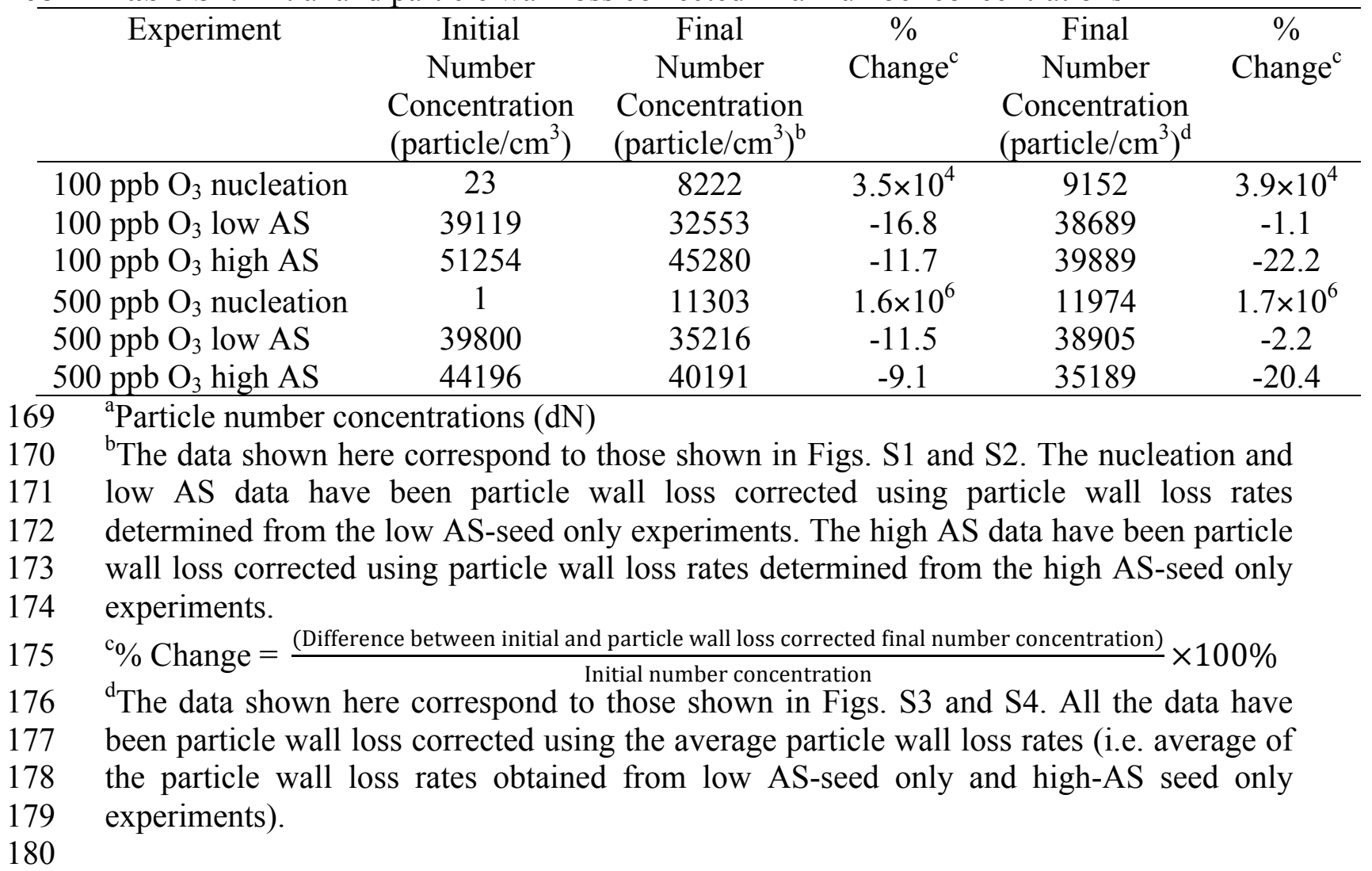

181

182

183

184

185 
$191 \quad$ Table S2: Discretization of parameters

\begin{tabular}{ll}
\hline Parameter & \multicolumn{1}{c}{ Discretization } \\
\hline$\alpha_{p}$ & $1,0.1,0.01,0.001$ \\
$\alpha_{w}$ & $10^{-7}, 10^{-6}, 10^{-5}$ \\
$\tau_{\text {olig }}$ & $4,6,8$ \\
$>10^{3}$ branching ratio $^{\mathrm{a}}$ & $0.5,0.6,0.7,0.8,0.9,1$ \\
$10^{2}$ branching ratio $^{\mathrm{a}}$ & $0,0.1,0.2,0.3,0.4,0.5$ \\
10 branching ratio $^{\mathrm{a}}$ & $0,0.01,0.02,0.03,0.04,0.05,0.1,0.15,0.2$ \\
1 branching ratio $^{\mathrm{a}}$ & $0,0.01,0.02,0.03,0.04,0.05,0.1,0.15,0.2$ \\
0.1 branching ratio $^{\mathrm{a}}$ & $0,0.01,0.02,0.03,0.04,0.05,0.1,0.15,0.2$ \\
\hline
\end{tabular}

192 anly combinations of parameters summing to one were allowed.

193

194

195

196

197

198

199

200

201

202

203

204

205

206

207 
208 Table S3: Comparison of experimental conditions used in this work with those of 209 previous dark $\alpha$-pinene ozonolysis studies. The SOA mass yields and concentrations of 210 these studies are shown Fig. 5.

\begin{tabular}{|c|c|c|c|c|c|c|}
\hline Study & $\begin{array}{l}\text { Temperature } \\
\text { (K) }\end{array}$ & $\begin{array}{l}\mathrm{RH} \\
(\%)\end{array}$ & Seed & $\begin{array}{c}\mathrm{OH} \\
\text { Scavenger }\end{array}$ & $\begin{array}{c}\mathrm{O}_{3} \\
(\mathrm{ppb})\end{array}$ & $\begin{array}{l}\Delta \mathrm{HC} \\
(\mathrm{ppb})\end{array}$ \\
\hline Cocker et al. $(2001)^{\mathrm{a}}$ & $301.2-302.9$ & $\begin{array}{c}<2,39- \\
49.2\end{array}$ & $\begin{array}{c}\text { None, } \\
\left(\mathrm{NH}_{4}\right)_{2} \mathrm{SO}_{4} \\
\text { and } \mathrm{NH}_{4} \mathrm{HSO}_{4}\end{array}$ & 2-butanol & $130-600$ & $\begin{array}{l}22.6- \\
212.3\end{array}$ \\
\hline Gao et al. $(2004)^{\mathrm{b}}$ & 293 & 55 & $\mathrm{MgSO}_{4}$ & cyclohexane & $24-270$ & $12-135$ \\
\hline Griffin et al. (1999) & 303.3-309.9 & 5 & $\left(\mathrm{NH}_{4}\right)_{2} \mathrm{SO}_{4}$ & 2-butanol & $67-260$ & $16.7-65$ \\
\hline Hoffmann et al. (1997) & $289.3-322.1$ & N.A. & $\left(\mathrm{NH}_{4}\right)_{2} \mathrm{SO}_{4}$ & None & $210-327$ & $38-154.1$ \\
\hline Pathak et al. (2007b) & $288-313$ & $<10$ & $\begin{array}{c}\text { None, } \\
\left(\mathrm{NH}_{4}\right)_{2} \mathrm{SO}_{4}\end{array}$ & 2-butanol & $\begin{array}{l}750- \\
3100\end{array}$ & $3.7-8.5$ \\
\hline Presto et al. $(2005)^{\mathrm{c}}$ & 295 & $<10$ & None & 2-butanol & $160-605$ & $15-210$ \\
\hline Presto et al. $(2006)^{\mathrm{d}}$ & 295 & $<10$ & None & 2-butanol & $260-350$ & $13.4-135$ \\
\hline Shilling et al. $(2008)^{\mathrm{e}}$ & 298 & 40 & $\left(\mathrm{NH}_{4}\right)_{2} \mathrm{SO}_{4}$ & $\begin{array}{l}1-\text { and } 2- \\
\text { butanol }\end{array}$ & $\begin{array}{c}50,300 \\
535\end{array}$ & $0.3-22.8$ \\
\hline Song et al. $(2007)^{f}$ & $300.6-301.7$ & $<2$ & None & cyclohexane & 46-369 & $5.9-81.1$ \\
\hline This study & 298 & $<5$ & $\left(\mathrm{NH}_{4}\right)_{2} \mathrm{SO}_{4}$ & cyclohexane & 100,500 & $42.4-52.1$ \\
\hline
\end{tabular}

$211{ }^{\mathrm{a}}$ Data collected using aqueous seed aerosol is excluded from our analysis.

$212{ }^{\mathrm{b}}$ Data collected using acidic seed aerosol is excluded from our analysis.

$213{ }^{c}$ Only dark experiments in which $[\alpha-$ pinene $] /\left[\mathrm{NO}_{\mathrm{x}}\right]>15$ are used in our analysis.

214 donly dark $\alpha$-pinene ozonolysis experiments are used in our analysis.

215 'Data collected in batch mode and continuous-flow mode are used in our analysis.

216 f Data collected using organic seed aerosol is excluded from our analysis.

217

218

219

220

221

222

223

224

225

226 
227 Table S4: Best-fit parameters, using lowest percentage error and Karnezi et al. (2014) 228 method

\begin{tabular}{lcc}
\hline Parameter & Lowest percentage error & $\begin{array}{c}\text { Karnezi et al. (2014) } \\
\text { method }\end{array}$ \\
\hline$\alpha_{p}$ & 0.1 & 0.35 \\
$\alpha_{w}$ & $10^{-6}$ & $3.6 \times 10^{-6}$ \\
$\tau_{\text {olig }}(\mathrm{h})$ & 4 & 6 \\
$>10^{3}$ branching ratio & 0.6 & 0.66 \\
$10^{2}$ branching ratio & 0.3 & 0.16 \\
10 branching ratio & 0.05 & 0.06 \\
1 branching ratio & 0.05 & 0.06 \\
0.1 branching ratio & 0 & 0.06 \\
\hline Percentage error for & $\mathbf{2 1 \%}$ & $\mathbf{3 7 \%}$ \\
combination & &
\end{tabular}

